\title{
ERRATA
}

\section{Capsular Polysaccharide of Clostridium perfringens Hobbs 9}

\author{
ROBERT CHERNIAK* AND HAROLD M. FREDERICK
}

Department of Chemistry, Georgia State University, Atlanta Georgia 30303

Volume 15 , no. 3 , p. 767 : Because of a printing error, Table 2 is incorrect as printed. The table should read as follows:

TABLE 2. Purification of the capsular polysaccharide of C. perfringens Hobbs 9

\begin{tabular}{|c|c|c|c|c|c|c|c|c|c|}
\hline \multirow[b]{2}{*}{ Step } & \multirow[b]{2}{*}{ Fraction isolated } & \multirow[b]{2}{*}{$\begin{array}{l}\text { Fraction } \\
\text { treated (g) }\end{array}$} & \multirow{2}{*}{\multicolumn{2}{|c|}{ Treatment }} & \multirow{2}{*}{$\begin{array}{l}\text { Amt re- } \\
\text { covered } \\
(\% \text { by wt) }\end{array}$} & \multicolumn{4}{|c|}{$\begin{array}{c}\text { Composition ( } \% \text { by wt) of isolated frac- } \\
\text { tion }\end{array}$} \\
\hline & & & & & & $\begin{array}{l}\text { Car- } \\
\text { bohy- } \\
\text { drate }\end{array}$ & Protein & $\begin{array}{l}\text { Phos- } \\
\text { phate }\end{array}$ & $\begin{array}{l}\text { Hexosa- } \\
\text { mine }\end{array}$ \\
\hline 1 & $\begin{array}{l}\text { Crude polysac- } \\
\text { charide }\end{array}$ & 62 (cells) & $0.85 \% \mathrm{NaCl}$ & & 9.0 & 16 & 21 & 24 & 1.9 \\
\hline 2 & Supernatant 0 & 5.6 & $\left(\mathrm{NH}_{4}\right)_{2} \mathrm{SO}_{4}$ & & 20.4 & 17 & 29 & 21 & 5.2 \\
\hline 3 & $\begin{array}{l}\text { Supernatant } \\
\text { O-RP }\end{array}$ & 1.0 & RNase $^{a}$-Papain & & 41 & 21 & 10 & 15 & 8.4 \\
\hline 4 & $\begin{array}{l}\text { Supernatant } \\
\text { O-RPD }\end{array}$ & 0.35 & $\begin{array}{l}\text { DEAE-Sephadex } \\
(15 \mathrm{~cm})\end{array}$ & A25 & 43 & 24 & 3.8 & 3.2 & 14.2 \\
\hline 5 & $\begin{array}{l}\text { Supernatant } \\
\text { O-RPDA }\end{array}$ & 0.042 & Agarose $1.5 \mathrm{M}$ & & 83 & 31 & 3.1 & 2.8 & 14.7 \\
\hline \multirow[t]{4}{*}{6} & $\begin{array}{l}\text { Supernatant } \\
\text { O-RPD2 }\end{array}$ & 0.116 & $\begin{array}{l}\text { DEAE-Sephadex } \\
(30 \mathrm{~cm})\end{array}$ & $\mathbf{A 2 5}$ & 45 & & & & \\
\hline & Peak IA & & & & & $\mathrm{ND}^{b}$ & $6.0^{c}$ & 7.6 & 17.6 \\
\hline & Peak IB & & & & & ND & 5.3 & 7.5 & 18.3 \\
\hline & Peak II & & & & & ND & 5.6 & 1.6 & 23.2 \\
\hline
\end{tabular}

a Ribonuclease.

b ND, Not done.

c Calculated by amino acid composition.

\section{Penicillin Sensitivity and Serum Resistance Are Attributes of Strains of Neisseria gonorrhoeae Causing Disseminated Gonococcal Infection}

\author{
B. I. EISENSTEIN,* T. J. LEE, AND P. F. SPARLING \\ Department of Medicine, University of North Carolina School \\ of Medicine, Chapel Hill, North Carolina 27514
}

Volume 15 , no. 3 , p. 835 , 2nd column, line 39: Change " 0.25 " to read " 0.025 ." 